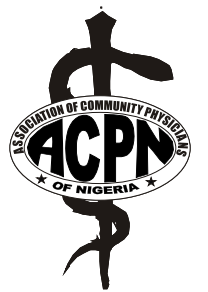

\title{
Female genital cutting among the Hausa community in Sagamu
}

\section{Oduwole and CA lyaniwura}

\author{
Department of Community Health and Primary Health Care, Olabisi Onabanjo University Teaching Hospital, \\ Sagamu
}

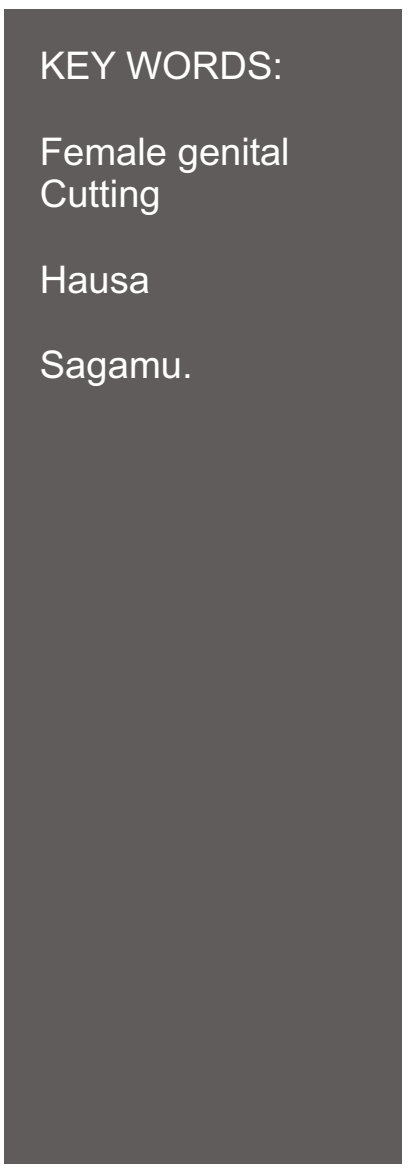

\section{Abstract}

Context: Female genital cutting is a prevalent practice in many parts of Nigeria but anecdotal evidence shows that Sagamu indigenes do not practice it. This study examined the awareness, attitude and practice of female genital cutting among the Hausas who reside in Sagamu.

Methodology: A cross-sectional study was carried out in Sabo, Sagamu, in the months of May/June 2002. Multi-staged sampling technique was used to choose 245 respondents from the study area.

Results: One hundred and seventy seven females and 68 males were interviewed. The males had a higher level of education compared with the females $(p<0.05)$. Female genital cutting was a prevalent practice in the community as $80 \%$ of all the respondents were aware of the practice and $69.9 \%$ of the females reported that they were circumcised. The most commonly performed type was Type 1 (sunna), which is usually performed in the first week of life by traditional birth attendants and barber surgeons.

The commonly cited reasons for the practice were: to ease delivery (20.6\%), religious injunctions $(19.1 \%)$ and tradition (15.5\%). At the household level, fathers were the major decision-makers about female circumcision. The females in the study had a more conservative attitude to female genital cutting, as they tended to support the practice more than the males $(64.8 \%$ females and $20.5 \%$ males). The males were more likely to be aware of the campaign against FGC and were more likely to support the campaign $(p<0.05)$.

Conclusion: Female genital cutting is a prevalent practice among the study population. There is a need to improve female education among this population, intensify anti-FGC campaigns and more specifically target information at the women.

\section{Introduction}

Female Genital Cutting (FGC) is a prevalent practice in more than 28 countries in Africa and some Asian countries. It is estimated that almost 2 million girls are at risk of undergoing the procedure every year. ${ }^{1}$ The procedure can be associated with several complications such as severe pain, hemorrhage, infections, risk of HIV infection and injury to adjacent organs. Long term damage to reproductive and sexual health and psychological consequences can also occur with severe types. ${ }^{2}$

Various efforts have been made by government, nongovernmental organizations (NGOs) and international organizations such as Inter-African Committee for the Abolition of Traditional Practices Harmful to women and children (IAC) to eliminate the practice through community education, policy-making and legislation ${ }^{3}$. However, at the community level, the various policies and programmes are confronted by myths, beliefs, values and code of conduct, which ensure that individuals conform to the practice ${ }^{4}$. Good understanding of the context of this cultural practice among communities that practice it is necessary to design relevant and effective strategies for change.

Although anecdotal evidence shows that indigenes of Sagamu do not practice FGC, this study was carried out among the Hausa community living in Sagamu, Ogun State to examine their knowledge, beliefs and practice of FGC, their awareness and attitude towards the campaign against FGC. Although FGC may not affect men directly, it is known 
that male attitude may affect reproductive behaviour of females. Hence this study also examined the attitude of males to the practice.

\section{Background to the Study}

The Sagamu local government is situated in Ogun State in the Southwestern part of Nigeria. It has an estimated population of about 205,854 (1991population census). Sagamu town is the headquarters of Sagamu Local government Area of Ogun State. Sabo is one of the wards in Sagamu and Agura is an area in Sabo ward. Although Sagamu town is inhabited predominantly by Yorubaspeaking people, the Sabo community is cosmopolitan in nature with ethnic groups from all over Nigeria resident there. Members of the Hausa tribe live almost exclusively in the Agura area of Sabo and they have their own leader.

Sagamu is one of the major towns in Remo land. Although the practice of infant circumcision is highly prevalent among the Yorubas, anecdotal evidence shows that Remo indigenes of Ogun State do not practice female circumcision. The health status of the people is similar to that of the whole country. It is characterized by a high infant mortality, high fertility rate and low life expectancy. Private and public health institutions as well as local traditional healers provide health care to the people.

\section{Methodology}

The study was conducted among the Hausa who reside in Agura area of Sabo, Sagamu in the months of May/June 2002. Consent to carry out the study was given by the leader of the Hausa community who also appointed a community leader to introduce the interviewers to the community members. Males and females aged between 10 and 65 years constituted the target population for this study.

Two female university undergraduates and a male (selected from the community) who understood both Hausa and English were trained in the administration of the questionnaire to facilitate the data collection process. The multi-stage sampling technique was used to select 245 respondents from the study area. The questionnaire was pre-tested among women in a similar ward in Sagamu and necessary corrections were made before applying them to the study group. The purpose of the study was explained to eligible individuals and those who consented were interviewed using a structured, interviewer-administered questionnaire.

The questionnaire was designed to gather information about the socio-demographic characteristics of the respondents, their knowledge, attitude and practice of FGC and also their attitude towards its eradication. Only the females were asked whether they had been circumcised. For those who indicated that they had been circumcised, the interviewers explained to them the various types of circumcision and the respondents indicated the type that had been performed on them.
Circumcision status was based on self -report alone. The result was collated and analyzed using the Statistical Package for Social Sciences. The results are presented in frequency tables and chi-square was used to determine statistical differences between groups (significance level $\mathrm{p}<0.05)$.

\section{Results}

A total of 245 respondents ( 177 females and 68 males) were involved in the study.

Table 1 shows that there was no significant difference in the age distribution of the respondents though a greater proportion of the females were older than 60 years $(12.4 \%$ compared to $1.5 \%$ of the males). Majority $(99.2 \%)$ of the respondents were Muslims. The males were more likely to be single and a higher percentage of the males $(51.5 \%)$ had secondary and post secondary education compared to $21.0 \%$ of the females.

One hundred and ninety four respondents $(79.2 \%)$ were aware of the practice of female genital cutting in their community. Among those who were aware of the practice, community members $(42.3 \%)$, religious institutions $(23.7 \%)$ and mass media (16.5\%) were the commonest sources of information about FGC. More than half (51.5\%) of the women who were aware of FGC mentioned community members as their source of information compared to $20.7 \%$ of the males while $48.3 \%$ of the males mentioned the mass media as their source of information compared to $2.9 \%$ of the females. Majority of those who were aware of the practice $(77.2 \%)$ believed that the procedure is not associated with any complication while $15.4 \%$ reported that it is sometimes associated with mild bleeding which subsides with some traditional applications and in a few cases hospital management. No mortality was attributed to the procedure.

One hundred and twenty three females $(69.5 \%)$ indicated that they were circumcised, $18(10.2 \%)$ had not been circumcised while 36 (20.3\%) did not know whether they had been circumcised or not. Of the circumcised females, $98(79.9 \%)$ had type one circumcision (sunna), $0.8 \%$ underwent type two (clitoridectomy) while $19.3 \%$ did not know the type performed on them. According to the respondents, types III and IV are not practiced among them because it is associated with a lot of complications. Ninetythree percent were circumcised within the first week of life. Traditional birth attendants (68.3\%) and barber surgeons $(27.6 \%)$ circumcised the majority of them at home using a small knife commonly called aska (88.2\%).

Table 2 show that there were gender differences in the reasons given by the males and females for the practice. Of the hundred and ninety-four respondents (58 males and 136 females) who were aware of the practice in their community, $82.5 \%$ could proffer at least one reason for the practice. Women were more likely to believe that FGC makes delivery easy $(27.2 \%)$, initiates girls into womanhood $(12.5 \%)$ and prevents promiscuity $(11.0 \%)$. The most common reason cited by males was that it was a religious injunction (44.8\%) while none of them mentioned that it prevents promiscuity.

Males play a significant role in the decision to circumcise 


\begin{tabular}{|c|c|c|c|c|c|c|}
\hline Variables & $\begin{array}{c}\text { Males } \\
\text { Freq }\end{array}$ & $\begin{array}{l}\mathrm{N}-68 \\
\%\end{array}$ & $\begin{array}{l}\text { Female } \\
\text { Freq. }\end{array}$ & $\begin{array}{l}\mathrm{N}-177 \\
\%\end{array}$ & $\begin{array}{l}\text { Total } \\
\text { Freq }\end{array}$ & $\begin{array}{l}\mathrm{N}-245 \\
\%\end{array}$ \\
\hline \multicolumn{7}{|l|}{ Aaes } \\
\hline $10-19$ & 7 & 10.3 & 33 & 18.8 & 40 & 16.4 \\
\hline $20 \quad 29$ & 23 & 33.8 & 73 & 40.8 & 96 & 38.9 \\
\hline $30 \quad 39$ & 15 & 22.1 & 33 & 18.7 & 48 & 19.7 \\
\hline $40 \quad 49$ & 15 & 22.1 & 16 & 9.1 & 31 & 12.7 \\
\hline$>50$ & 8 & 11.8 & 22 & 16.8 & 30 & 12.4 \\
\hline Total & 68 & 100.0 & 177 & 100.0 & 245 & 100.0 \\
\hline \multicolumn{7}{|l|}{ Religion } \\
\hline Christianity & 1 & 1.5 & 1 & 0.6 & 2 & 0.8 \\
\hline Islam & 67 & 98.5 & 176 & 99.4 & 243 & 99.2 \\
\hline Total & 68 & 100.0 & 177 & 100.0 & 245 & 100.0 \\
\hline \multicolumn{7}{|l|}{$\begin{array}{l}\text { Marital } \\
\text { status* }\end{array}$} \\
\hline Single & 32 & 47.1 & 29 & 16.5 & 61 & 24.2 \\
\hline Married & 36 & 52.9 & 132 & 74.4 & 168 & 69.7 \\
\hline Widowed & - & - & 16 & 9.1 & 16 & 6.6 \\
\hline Total & 68 & 100.0 & 177 & 100.0 & 245 & 100.0 \\
\hline \multicolumn{7}{|l|}{ Education } \\
\hline None & 6 & 8.8 & 32 & 18.2 & 38 & 15.6 \\
\hline Islamic & 15 & 22.1 & 66 & 37.5 & 81 & 33.2 \\
\hline Primary & 12 & 17.6 & 41 & 23.3 & 53 & 21.7 \\
\hline Secondary & 27 & 39.7 & 32 & 17.6 & 59 & 23.7 \\
\hline Post & 8 & 11.8 & 6 & 3.4 & 14 & 5.7 \\
\hline \multicolumn{7}{|l|}{ Secondary } \\
\hline Total & 68 & 100.0 & 177 & 100.0 & 245 & 100.0 \\
\hline
\end{tabular}

\begin{tabular}{|c|c|c|c|c|c|c|}
\hline \multirow[t]{2}{*}{ Reasons } & \multicolumn{2}{|l|}{ Male } & \multicolumn{2}{|c|}{ Female } & \multicolumn{2}{|l|}{ Tota } \\
\hline & Freq & $\%$ & Freq & $\%$ & Freq & $\%$ \\
\hline Religion & 26 & 44.8 & 11 & 8.1 & 37 & 19.1 \\
\hline Make delivery easy & 3 & 5.2 & 37 & 27.2 & 40 & 20.6 \\
\hline Prevent Promiscuity & . & $\cdot$ & 15 & 11 & 15 & 7.7 \\
\hline Tradition & 5 & 8.6 & 25 & 18.3 & 30 & 15.5 \\
\hline $\begin{array}{l}\text { Initiate girl into } \\
\text { womanhood }\end{array}$ & 1 & 1.5 & 17 & 12.5 & 18 & 9.3 \\
\hline $\begin{array}{l}\text { Cause baby's death } \\
\text { during delivery }\end{array}$ & 3 & 4.4 & 2 & 1.5 & 5 & 2.6 \\
\hline For health of woman & $\cdot$ & $\cdot$ & 3 & 2.2 & 3 & 1.6 \\
\hline I dont know & 20 & 34.5 & 26 & 19.1 & 46 & 23.7 \\
\hline Total & 58 & 100.0 & 136 & 100.0 & 194 & 100.0 \\
\hline
\end{tabular}

girls. At the household level, fathers were the main decision makers about circumcision of girls. Only $7.4 \%$ of the females and none of the males indicated the woman as the decision maker. The females $(64.8 \%)$ were more likely to believe that girls should be circumcised compared to $20.5 \%$ of the males $(p<0.005)$. However, of those interviewed, none of the females was a circumciser while $14.7 \%$ of the males were circumcisers.

A higher proportion of males $(69.1 \%)$ was aware of the campaign against FGC compared to only $16.5 \%$ of females. Majority of those who were aware heard from the mass media especially the radio $(84.9 \%)$ and friends. Table 3 shows that over half ( $53.9 \%$ ) of respondents who were mainly females did not know of the campaign against FGC and had no opinion for or against it. A significant proportion $(31.4 \%)$ of the respondents however supported the campaign. The reasons given for supporting the campaign were that FGC is wrong $(40.6 \%)$, causes health problems (25.0\%), is not supported by Islam (15.6\%), and reduces sexuality/can cause HIV (12.5\%). Others included the fact that the practice was against the Hausa culture and also can cause laziness in those circumcised.

\begin{tabular}{|c|c|c|c|c|c|c|c|}
\hline Support & Male & $\%$ & Female & $\%$ & Total & $\%$ & $P$ value \\
\hline Yes & 47 & 69.1 & 30 & 16.5 & 77 & 31.4 & \\
\hline No & 10 & 14.7 & 19 & 10.8 & 29 & 11.8 & $p=0.0000$ \\
\hline I dont know & 11 & 16.2 & 128 & 72.7 & 139 & 53.9 & $X^{2}=70.49$ \\
\hline Total & 68 & 100.0 & 177 & 100.0 & 245 & 100.0 & $d f=2$ \\
\hline
\end{tabular}

\section{Discussion}

FGC is a prevalent practice in Nigeria though with wide variation according to region and ethnicity. ${ }^{5}$ Many people are aware of it in the communities where it is practiced. ${ }^{6}$ In this study, majority of the females had been circumcised. A nationwide study of the prevalence of FGC conducted in 2001/2 shows that the practice varies widely among different groups in the Northern State of Nigeria. While the practice was as low as $5 \%$ in Taraba State, Yobe $(20 \%)$, Sokoto (32\%), it was widely practiced in Adamawa (72\%), Kano $(80 \%)$, Katsina $(95 \%)$ and Kebbi $(100 \%)^{7}$. It is also not surprising that one fifth of the females in this study did not know whether or not they had been circumcised since FGC is commonly performed at infancy. This fact is corroborated by the 1999 DHS Survey which showed that majority of those who were circumcised had the procedure performed during infancy, especially in the first week of life $^{5}$.

Hausa barbers and the native doctors mostly performed the procedure in this study. Unfortunately, there is no standard to guide their practice, which may increase the risk of complications due to the procedure. In some 
the risk of complications due to the procedure. In some countries, as a response to concerns about the risks associated with the procedure, there have been moves to "medicalize" the procedure, that is, the involvement of health care workers in the performance of $\mathrm{FGC}^{2}$. This was also observed in a survey of women in a semi-urban town of Rivers State, Nigeria which showed that medical doctors were the most commonly mentioned practitioners of $\mathrm{FGC}^{8}$.

Religion was the most common reason given by the males in this study for FGC. This is not surprising because it has been found that some adherents of the strongest reasons reported to support $\mathrm{FGC}$ is that it is a religious rite ${ }^{10}$. Since the fathers are the major decision makers about female circumcision and many of them cited religious injunction as the reason for FGC, any program aimed at eradicating this practice in the study population should work with religious leaders.

Among the women, it was widely believed that FGC facilitates easy delivery. This is similar to what was found in Owu quarters in Abeokuta, Ogun State, Nigeria, where FGC is performed because it is believed that a baby will die if the head touches the clitoris during delivery ${ }^{11}$. Every woman wants her children and her children's babies to survive. This concern about their children's future reproductive performance may challenge anti-FGC messages especially among communities with low levels of literacy and low female literacy in particular. These cultural beliefs must be adequately addressed by health education and facts. Tradition is a very important factor in parents' decision to circumcise their female child where people believe that the practice must continue because it has always been with them. ${ }^{11}$ However, in this study, few respondents indicated culture as a reason for FGC.

Some of the women also believed that FGC prevents promiscuity. Contrary to previous belief that FGC causes frigidity, recent findings suggest that genital cutting does not make a woman frigid ${ }^{12,13}$, but it shifts the point of maximal sexual stimulation from the clitoris to the breast and labia minora. In a study conducted among 1,836 women in Benin, Okonofua et al found that women who had undergone FGC were just as likely as those who had not to report having had recent sexual intercourse and were more likely to report sometimes initiating sexual intercourse with their partners. ${ }^{13}$ This myth should be addressed during health education sessions.

As expected of a patriarchal society, fathers mainly decided on whether their female children should be circumcised. It was said that once a female child has been born in any family among the Hausa community, the operators (TBA or Barbers) seek the consent of the father and proceed to circumcise the child in the parent's home. It is thus encouraging to note that over two-thirds of males in this study believed that girls should not be circumcised. This is similar to findings of a study conducted in 1987 in the middle belt of Nigeria which showed that almost two thirds of the males did not support female circumcision ${ }^{14}$. However, males are the circumcisers and the major decision-makers; hence, there is a need to continually reach out to this group.
Despite this, females cannot be underestimated in the move to eradicate FGC practice ${ }^{9}$. Majority of the females supported FGC compared to the males and they were also more likely to believe the myths about FGC such as that FGC prevents infant mortality and promiscuity. This is not surprising because the females were less educated compared to the men in the study; they were more likely to cite community members as their source of information about FGC and had less access to media messages including messages on the campaign against FGC. This underscores the need to educate females and specifically target them for health education programs and messages.

The major source of information about campaign against FGC was the mass media. This medium may not effectively reach out to women who are less educated and/or may not have access to the mass media. Innovative ways of targeting information at the women should be explored.

In conclusion, this study shows that FGC is still widely practiced among the Hausa community in Sagamu though the host community is not known to practice it. This emphasizes the need to study minority groups and that general assumptions cannot be made for whole communities where minority groups who still uphold ageold traditions exist. While some people see FGC as a traditional practice like any other which should not be subject to "cultural imperialism" by Europeans ${ }^{15}$, others see it as a health problem and a human rights abuse issue that should be adequately addressed. Meanwhile, the practice continues and millions of girls and ladies continue to suffer from its immediate and long-term complications.

Based on the findings of this study, the following recommendations are hereby made:

There is a need for strong and sustained political will on the part of the government which must translate into improved funding and commitment to programmes that improve the welfare of women and children. To encourage sustainability, FGC eradication programmes must be incorporated into regular activities in the community. Policies to encourage female education should be put in place and enforced to improve the educational status of women. Youths are important agents of change in the society. Therefore school children should be taught about the effects of harmful traditional practices including FGC.

Innovative ways of getting information across to women should be developed. FGC eradication programmes should be integrated into Primary Health Care with information regularly targeted at women during antenatal care, post natal care, infant and child welfare services. Non-governmental organizations, community-based organizations and religious groups should be encouraged to incorporate information about the negative effects of FGC into their programmes. The circumcisers should be educated about the negative effects of FGC, the need to stop the practice and where necessary obtain skills in other income generating activities.

\section{References}

1. World Health Organization (WHO). Female Genital Mutilation. Report of WHO Technical Working 
Group 17-19 July 1995. Geneva, WHO, 1995.

2. World Health Organization (WHO). Female Genital Mutilation: An Overview. Geneva, Switzerland, WHO, 1998.

3. Inter-African Committee on Traditional Practices Affecting the Health of Women, Addis Ababa July 2003. "What is female genital mutilation?" http://www.iacciaf.ch/FGM.htm.

4. World Health Organization (WHO). Female Genital Mutilation Programmes to date: What works and what doesn't. Geneva, WHO, 1999.

5. $\quad$ Federal Office of Statistics (FOS), Nigeria Demographic Health Survey, 1999. Calverton, Maryland, Macro International.

6. Abubakar I, lliayasu Z, Kabir M, Uzoho CC, Abdukadir M B. Knowledge, attitude and practice of female genital cutting among antenatal patients in Aminu Kano Teaching Hospital, Kano. Niger J Med. 2004 JulSep; 13(3): 254-8

7. Nigerian Centre for Gender, Health and Human Rights (NCGHHR), Law and Human Rights, Annual report 2001/2002. http://ncghr.tripod.com/humanrights/d9.html.

8. Ugboma HA, Akani Cl, Babatunde S. Prevalence and medicalization of female genital mutilation, Niger $\mathrm{J}$ Med. 2004 Jul-Sep; 13(3): 250-3
9. Sunday J and Austeg B. Female Genital Mutilation. A new challenge for the services. Tidsskrift for Den Norske Leageforening, 1993; 113 (21): 2704 - 2707.

10. Poulter $\mathrm{S}$. The significance of ethnic minority customs and traditions in English criminal law. New Community, 1989; 16 (1): 121-128.

11. Adeneye AK. 1995 Female circumcision in South West Nigeria: A case study of Owu Abeokuta, Ogun State Unpublished B Sc Thesis submitted to the department of Sociology, Ogun State, Ago-Iwoye.

12. Megafu U. Female ritual circumcision in Africa: An investigation of the presumed benefits among lbos of Nigeria. EastAfr Med J, 1983; 60: 793 - 800.

13. Okonofua FE, Larsen U, Oronsanye F, Snow RC, Slanger TE. The association between Female Genital Cutting and correlates of sexual and genaecological morbidity in Edo State, Nigeria. British Journal of Obstetric and Gynaecology, 2002; 109 (10): 1089 - 1096.

14. Ebomoyi E. Prevalence of female circumcision in two Nigerian communities.

15. Journal of Sex Roles, 1987; (17): $139-151$

16. Kedar M. Islam and "female circumcision': The dispute over FGM in the Egyptian press. Med Law, 2002; 21(2): 403-18 